\title{
The role of public-private partnerships in financing infrastructure projects
}

\author{
Samira Yakubova ${ }^{1}$, Sevara Yunusova ${ }^{1}$, Nargiza Shaislamova $^{1}$, Sherzodbek Murodov ${ }^{2 *}$, \\ Nuriddin Avazov ${ }^{3}$, and Nodirjon Shovkatov ${ }^{3}$ \\ ${ }^{1}$ Tashkent Institute of Finance, 100000, A.Temur Street 60A, Tashkent, Uzbekistan \\ ${ }^{2}$ Tashkent institute of irrigation and agricultural mechanization engineers, 39, Kari Niyazov \\ Street, 100000, Tashkent, Uzbekistan \\ ${ }^{3}$ Tashkent State University of Economics, 49 Uzbekistan street, 100003, Tashkent, Uzbekistan
}

\begin{abstract}
Poor infrastructure quality hinders the country's stable economic growth and competitiveness in international markets. The quality of life declines when the infrastructure is underdeveloped. Public-private partnership allows attracting additional sources of funding and receiving additional privileges from the state. Public-private partnerships in infrastructure benefit the economy, national politics, the private sector, as well as the population. The article examines the features of the formation and development of public-private partnerships in the development of the national economy of the Republic of Uzbekistan. The directions of innovative development are selected. The problems that require solutions for the continuous development of an innovative economy are identified. The aim of the study is to reveal the essence of public-private partnership in infrastructure, analyze the current state and its role, place in the economy of the Republic of Uzbekistan. The object of the research is economic relations in relation to public-private partnerships associated with the process of communication between the state and interested individuals, legal entities and international organizations. The subject of the research is the economic, social, legal aspect of the functioning of the forms of public-private partnership in the implementation of the functions of the state. The methodology laid the foundations for general scientific methods, general logical methods of cognition, systemic, logical, analysis, synthesis, deduction and induction, modeling and other methods. Based on the results of the study, conclusions were drawn to increase the attractiveness of PPP implementation in infrastructure.
\end{abstract}

\section{Introduction}

Infrastructure is a set of structures, buildings, systems and services that allow the economy to function and provide living conditions for the population. The most common PPPs in infrastructures are:

-Transportation infrastructure:

o Highways

* Corresponding author: sb.i.1@,mail.ru 
o Railways

o Airports, etc.

-Engineering infrastructure:

o Electricity

o Water supply and sewerage

o Gas supply

o Heat supply, etc.

-Social infrastructure:

o Healthcare

o Sports

o Education

o Culture

o Tourism and recreation, etc [1].

Infrastructure in the modern world requires certain large financial investments. The task of the state is to transfer large projects at the stage of development and design to the next stage - the stage of construction and operation. Infrastructure investment leads to overall economic growth. The World Bank estimates that a 10 percent increase in financial investment in infrastructure translates into a 1 percent increase in economic growth. Publicprivate partnership is one of the tools through which it is possible to increase the volume of investments in infrastructure and improve their efficiency [2].

From 2001 to 2008, the cost of infrastructure projects implemented all over the world using the mechanism of public-private partnership amounted to about $843 \mathrm{~B} 3$ billion dollars. Most of the infrastructure projects using PPPs are in Europe and Central Asia (23\%) and East Asia and the Pacific (18\%) [3].

A public-private partnership is an agreement between a private and a public party to provide infrastructure services to the public or to assist the state in providing these services. Service providers and a leading position, private sector participation, is critical to effective service delivery. The public-private partnership mechanism promotes the most effective participation of the private sector in public projects $[4,5]$.

Public-private partnership is an alternative to privatization, both politically and economically. The main difference between PPP and privatization is the ownership of an asset or object. In privatization, a state asset or enterprise, ownership and management is transferred to the private sector. In PPP projects, the state retains ownership and participation in the private sector project.

There are cases when privatization does not take place and PPP is applied. Under natural monopolies that supply consumers with products and services at low prices and meet the volume of demand with economies of scale. This includes utilities, rail infrastructure, the national fiber optic network, and others [6].

\section{Research methods}

Researching PPP in infrastructure requires certain scientific tools and methods. The methodology touches upon general logical, social methods of study. The most relevant are analysis, synthesis, deduction, grouping, and other methods. Using the toolkit of empirical and general logical methods, one can see a complete picture of the positive qualities of infrastructure projects, both for the state and for the private sector. Taking into account all the positive and negative aspects, theoretical conclusions are made that can correct the current state of infrastructure in the Republic of Uzbekistan. 


\section{Results}

Projects using public-private partnerships are very costly, require initial investments for project development, including project selection, preparation of a feasibility study, assistance from consultants involved in project development and tendering [7].

The most striking example of PPP in Uzbekistan is the construction of Tashkent City in the city of Tashkent, where the state provides support to private investors.

In countries with most of the participation in PPP projects, costs average $2.6 \%$ of capital costs, starting from the time of preparatory qualifications to financial closure, the preparatory process takes on average 3 years or more [8].

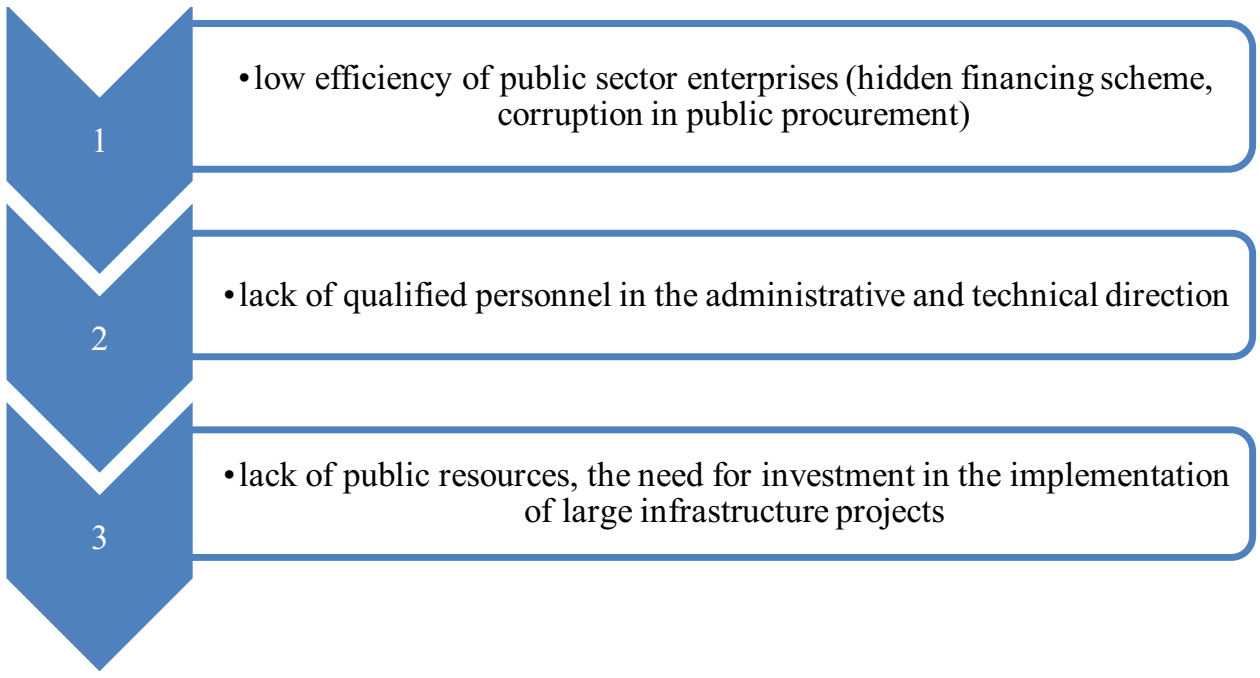

Fig. 1. Factors motivating the state to use public-private partnership.

Public-private partnership in practice is carried out in almost all areas where government agencies can act as a supplier, of which one can single out frequently encountered projects:

-Construction and modernization of infrastructure facilities (roads, power lines, airports)

-Social sphere (education, health care, social services)

- Utilities (formation and maintenance of utilities, repair of buildings)

-Applied science, innovations and new technologies (development and implementation of new technologies, production of models of equipment, industrial designs of goods) $[9,10]$.

Recently, Uzbekistan has begun to actively integrate PPPs in all spheres (education, economy, infrastructure, and so on). For the first time, the effect of the participation of the private sector in the economy was noticeable in 2017, the infrastructure began to develop rapidly. Since that time, PPP began to actively develop, on December 13, 2018, the law "On organizing the activities of the agency for the development of public-private partnership under the Ministry of Finance of the Republic of Uzbekistan" was adopted, on May 10, 2019, the law "On public-private partnership" was adopted, requirements increased to agencies by industry [11-14].

The PPP development program consists of three principles:

-forming the institutional and legislative framework

-forming a sustainable portfolio of infrastructure projects

- Justification of the choice of PPP and reduction of fiscal risk 
By the middle of 2020, more than 6 large projects were implemented in the Republic of Uzbekistan. In 2021, it is planned to implement more than 40 projects using PPP. This will be facilitated by the amendment to the PPP Law in January 2021. PPP is planned to be integrated into such areas as energy, healthcare, transport and so on.

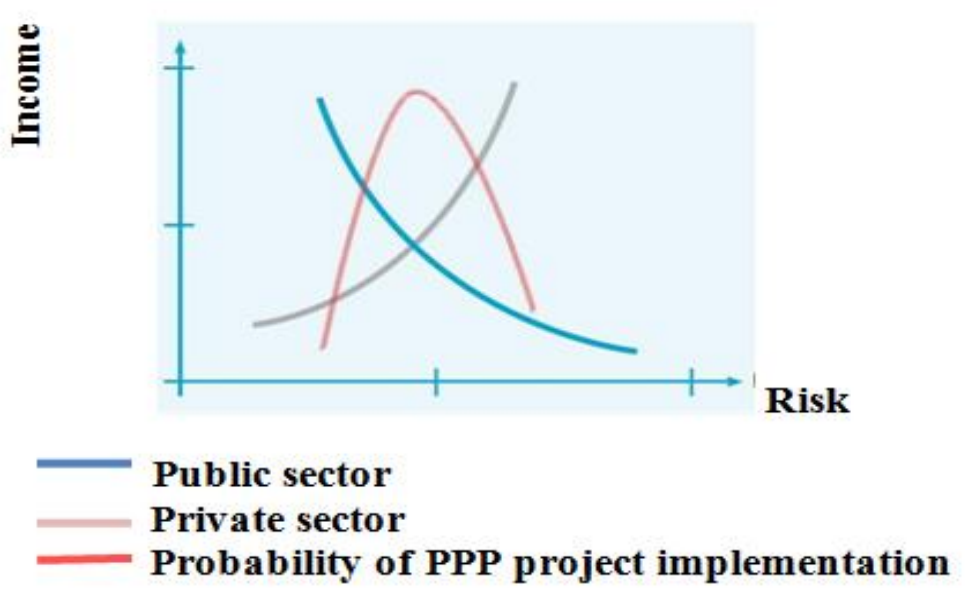

Fig. 2. Probability of success in implementing a public-private partnership, depending on the distribution of risks between its participants

Often, the technical condition of infrastructure facilities, which are financed by the state, do not meet the requirements, especially in developing countries. The PPP mechanism can increase the amount of finance by stimulating investment in the early stages. The concession is issued to a project company for a period of more than 25 years [15].

The socio-economic strategy of any region and country focuses on the development of infrastructure. The presence of an efficient infrastructure is a factor in the development of private enterprises in all sectors of the economy. The developed infrastructure allows to increase the inflow of investments.

In the world there is such a thing as "high expectations", in this case the private sector hopes for the state, something will build infrastructure, and the state expects the same, only from the private sector. The optimal solution is the implementation of infrastructure project financing using funds through state support methods. Infrastructure projects stimulate economic activity.

\section{Discussion}

Forms of partnership are divided into 3 groups, depending on the source of return on investment of the private partner.

1-Commercially attractive objects (for example, toll roads with a large flow), in this form the private partner will receive a sufficient amount of profit without paying from the budget. In this group, a classic concession is carried out, here the private partner is obliged to create or reconstruct the concession object and operate it according to the agreed period.

2-Private partner cannot make a return on investment through the operation of the facility. This includes, for example, free roads, most social infrastructure facilities. In this 
case, the return on investment is carried out through periodic payments from the budget, the amount of which is reduced if the private partner violates the terms of the contract.

3- Payments from the users of the project object - consumers (for example, owners of vehicles using a toll road), and from the budget. Here, the payment for the use of the object is partially reduced or the attractiveness of the project for the investor is increased due to the mechanism of the minimum guaranteed income (the state pays if the income of the private partner is below the minimum level agreed upon earlier) [16].

There is no optimal form of partnership; the form is selected according to the legal, financial and economic parameters of the project.

Public-private partnerships provide special benefits to both the state and the private partner.

Table 1. Main advantages of public-private partnerships.

\begin{tabular}{|c|l|l|}
\hline № & \multicolumn{1}{|c|}{ State } & \multicolumn{1}{|c|}{ Private partner } \\
\hline 1 & $\begin{array}{l}\text { Reducing the financial burden on the } \\
\text { budget }\end{array}$ & Constant stable return on invested capital \\
\hline 2 & Completion of the project in a short time & $\begin{array}{l}\text { Long-term stability of sales and capacity } \\
\text { utilization }\end{array}$ \\
\hline 3 & $\begin{array}{l}\text { Sharing part of the risks with a private } \\
\text { partner }\end{array}$ & Raising the company's rating \\
\hline 4 & $\begin{array}{l}\text { Active use of innovative technologies } \\
\text { Improving credit history and rating }\end{array}$ \\
\hline 5 & $\begin{array}{l}\text { Providing quality public services during } \\
\text { operation }\end{array}$ & \\
\hline
\end{tabular}

Like any other project, PPPs have their own risks. According to world experience, in the implementation of PPP projects, a large number of failures are associated with erroneous project counting and incorrect distribution of potential risks between partners. The Republic of Uzbekistan is a country with an economy in transition, it is very difficult to predict in the long term the indicators of economic growth of the economy, which are the basis for structuring PPP projects.

The main feature and advantage of PPP projects over direct budget financing is the possibility of transferring risks from the state to a private partner. If the analysis reveals a large number of risks associated with the implementation of the project, lenders may refuse to finance it. The main tool for risk analysis is the risk matrix, which is formed in PPP projects, on both sides of the public partner and the private partner. The PPP Law emphasizes effective risk sharing as one of the principles of PPP and identifies it as an important criterion for the agency when evaluating projects [17].

\section{Conclusion}

In the Republic of Uzbekistan, innovative projects are not carried out at the highest level of activity. It is necessary to coordinate the forces and capacities in terms of the formation of an innovative infrastructure, the development of innovative entrepreneurship, the improvement of the interaction of public authorities with the already existing elements of the innovation infrastructure, this includes research and educational centers, infrastructure for financing innovation and innovative companies. The PPP mechanism can serve as the basis for mutually beneficial partnership.

The development of PPP in infrastructure requires certain stages: 
1. Introduction of PPP into national infrastructure planning. PPP is one of the procurement instruments, with the help of this instrument the state can achieve infrastructure goals. PPP should be made part of the planning mechanism, for a start, it is necessary to build the capacity of agencies by industry, for more interest, the formation of a general cost estimate. The next step is structuring the policy and project selection mechanism to decide when the project should be implemented with PPP integration, not forgetting the value for money methodology. Next, training is carried out at the central planning agency to form the mechanism.

2. Potential payments. They are widespread all over the world, it is necessary to integrate the system to monitor and manage fiscal obligations in the medium term, and as the use increases, the provision of various possible payments.

3. Project Development Fund. To prepare PPP projects, large funds are spent on hiring consultants for technical and economic assessments, transaction consultants. The project development fund can hire transaction consultants to prepare and conduct a tender for the project, reimbursed through the tender fees.

4. Implementation of the project after financial closure. For the state, it is necessary to form a project monitoring group, and to form internal potential, since the closure of the project financing gives rise to a long concession period.

5.Participation of banks in PPP. In the Republic of Uzbekistan, the terms of the loan for project financing and the deposit base of banks do not correspond to each other, which leads to low liquidity in local currency for infrastructure projects. To mitigate this, it is recommended that a non-bank financial intermediary be established that is able to finance the project in local currency.

6. Uzbekistan in the world market. Uzbekistan should appear more in the media, as many large companies in the world are interested in bidding on projects in various sectors.

Implementation of infrastructure projects using PPP, a risk distribution system should be created that will reduce the cost of risks and measures to mitigate them. With this principle of risk management, the infrastructure project will create motivation for partners to effectively manage the project, helping to achieve the optimal ratio of costs and benefits from the implementation of a PPP project.

\section{References}

1. J. Delmon, Private Sector Investment in Infrastructure: Project Finance, PPP Projects and Risk (The World Bank and Kluwer Law International. The Netherlands, 2009)

2. N.N. Shash, Vector of science of the Tolyatti state university. Series: Economy and management 4 (23), 99-103 (2015)

3. V.G. Varnavsky, A.V. Klimenko, V.A. Korolev, Public-private partnership: theory and practice (M .: GU-HSE, 2010)

4. L.M. Igolkina, Economic sciences 3, 49-52 (2013)

5. Yu.S. Emelyanov, Public-private partnership: innovation and investment. World and domestic experience (M.: Book House "LIBROKOM", 2013)

6. N.A. Yusupov, F.E. Karabaev, Theory and practice of public-private partnership. Training module (Tashkent, 2013)

7. G.G. Dustmurodov, I.O. Yunusov, U.K. Ahmedov, S.M. Murodov, S.T. Iskandarov, E3S Web of Conferences 224, 04042 (2020)

8. I.V. Zapatrina, The Potential of public-private partnerships in emerging economies (K.: CENTROTEC, 2011)

9. V.P. Anikina, R.G. Abasov, Finance and credit 9, 45-50 (2013) 
10. M.A. Raimjanova, D.Kh. Shadiyeva, L.S. Zoyirov, R.B. Saidov, M.T. Askarova, of Conferences 244, 10044 (2021)

11. Law of the Republic of Uzbekistan "On public-private partnership" No. 537 dated $05 / 10 / 2019$

12. Law of the Republic of Uzbekistan "On the organization of activities of the agency for the development of public-private partnerships under the Ministry of Finance of the Republic of Uzbekistan" No. 1009 dated 13.12.2018

13. Decree of the President of the Republic of Uzbekistan of 07.02.2017, UP No. 4947 "On the strategy of actions for the further development of the Republic of Uzbekistan"

14. Decree of the President of the Republic of Uzbekistan dated 09.21.2018 "Strategy of innovative development of the Republic of Uzbekistan for 2019-2021"

15. N.N. Shash, S.V. Pravednov, Business. Education. Right. Bulletin of the Volgograd institute of business 2 (23), 117-119 (2013)

16. U. Sangirova, B. Tursunov, S. Shayakubov, I. Yunusov, D. Bababekova, E3S Web of Conferences 244, 10050 (2021)

17. C. Cottarelli, Public Private Partnerships. What are They? Theory and Practice (Deputy Director, Fiscal Affairs Department, IMF February, 2008) 